\title{
Inhibition of Forskolin-stimulated cardiac adenylate cyclase activity by short-chain alcohols
}

\author{
Patrick Robberecht, Magali Waelbroeck, Pierre Chatelain, Jean-Claude Camus and \\ Jean Christophe*
}

Department of Biochemistry and Nutrition, Medical School, Université Libre de Bruxelles, Bld. de Waterloo 115, B-1000 Brussels, Belgium

Received 21 February 1983

\begin{abstract}
The diterpene forskolin stimulated rat cardiac adenylate cyclase activity at least 20 -fold and potentiated the effect of $\mathrm{NaF}$. The stimulatory effect of forskolin was reduced in the presence of $\mathrm{Gpp}(\mathrm{NH}) \mathrm{p}$. Ethanol markedly reduced the stimulation of adenylate cyclase by forskolin while potentiating $\mathrm{NaF}$ and $\mathrm{Gpp}(\mathrm{NH}) \mathrm{p}$ stimulation. The inhibitory effect of ethanol on forskolin stimulation appeared to be of a mixed type with both a competitive and a non-competitive component. Three other short-chain linear alcohols (methanol, propanol, butanol) also inhibited forskolin-stimulation, this effect being proportional to the number of carbon atoms.
\end{abstract}

Adenylate cyclase Forskolin Short-chain alcohol Ethanol Rat heart

\section{INTRODUCTION}

This study aimed to evaluate, in rat cardiac membranes, the effect of short-chain alcohols on the stimulation of adenylate cyclase activity by the diterpene forskolin, a potent general activator of the enzyme $[1,2]$. This study was justified on theoretical and practical grounds:

(1) There are some similarities in the proposed site(s) of action of forskolin and alcohols on adenylate cyclase activity. Forskolin is supposed to act directly on the catalytic subunit of adenylate cyclase [3] and also on the coupling mechanism of guanine nucleotide regulatory sites $\left(\mathrm{N}_{s}\right.$ and $\left.\mathrm{N}_{\mathrm{i}}\right)$ with the catalytic subunit [4-6]. Alcohol stimulation of adenylate cyclase activity in membrane preparations is obvious when tested in the presence of $\mathrm{Gpp}(\mathrm{NH}) \mathrm{p}$ and $\mathrm{NaF}$ but more difficult to demonstrate when tested in the presence of hor-

* To whom correspondence should be addressed

Abbreviation: $\mathrm{Gpp}(\mathrm{NH}) \mathrm{p}, \quad$ guanosine 5 - $-O$ (2-3-imido)-triphosphate mone [7-10]. Furthermore, the effects of forskolin and alcohol observed in both intact cells and membranes are immediately reversible $[8,11]$. Finally, forskolin and alcohol are hydrophobic molecules.

(2) In most in vitro studies, forskolin is dissolved in ethanol and it was important to evaluate the effect of the solvent on the biological activity of the diterpene.

\section{MATERIALS AND METHODS}

Cardiac membranes were prepared from male rat hearts as in [12] and stored in liquid nitrogen until use at $6 \mathrm{mg}$ protein $/ \mathrm{ml}$. Adenylate cyclase activity was determined with minor modifications of the procedure in $[12,13]$. Forskolin was obtained from Calbiochem-Behring Corp. (La Jolla CA). A $30 \mathrm{mM}$ forskolin solution was prepared in absolute ethanol and further diluted in distilled water so that control experiments always had $<0.08 \mathrm{M}$ ethanol. It was verified that adenylate cyclase activity was linear with time under all conditions tested. 


\section{RESULTS}

Basal cardiac adenylate cyclase was stimulated 4.4-, 9.7- and 21.0 -fold by, respectively, maximally effective concentrations of $\mathrm{Gpp}(\mathrm{NH}) \mathrm{p}$ and $\mathrm{NaF}$, and a submaximal concentration of forskolin (table 1). The activity measured when forskolin and $\mathrm{NaF}$ were added simultaneously was higher than the sum of the individual effects; by contrast, the activity was lower than the sum of the individual effects when forskolin and $\mathrm{Gpp}(\mathrm{NH}) \mathrm{p}$ were added in combination, suggesting that cardiac membranes contain inhibitory guanine nucleotide regulatory proteins [5].

Ethanol at $0.1-1.0 \mathrm{M}$ was without significant effect on basal adenylate cyclase activity but markedly potentiated $\mathrm{NaF}$ as well as $\mathrm{Gpp}(\mathrm{NH}) \mathrm{p}$ stimulations. By contrast, ethanol markedly inhibited forskolin stimulation when tested in the same concentration range (fig.1). Dose-effect curves of forskolin activation of adenylate cyclase in the presence of increasing concentrations of ethanol revealed a progressive decrease in the maximal efficacy of the diterpene as well as a small but significant shift to the right of the concentration required for half-maximal enzyme stimulation (fig.2). These results suggest that the ethanol in-

Table 1

\begin{tabular}{lrr}
\hline Additions & $(n)$ & \multicolumn{1}{c}{$\begin{array}{c}\text { Adenylate } \\
\text { cyclase } \\
\text { activity }\end{array}$} \\
\hline Basal & $(11)$ & $25 \pm 1$ \\
Gpp(NH)p $100 \mu \mathrm{M}$ & $(7)$ & $111 \pm 5$ \\
$\mathrm{NaF} 10 \mathrm{mM}$ & $(7)$ & $243 \pm 13$ \\
$\begin{array}{l}\text { Forskolin } 30 \mu \mathrm{M} \\
\text { Forskolin } 30 \mu \mathrm{M}+ \\
\quad \text { Gpp(NH)p } 100 \mu \mathrm{M}\end{array}$ & $(11)$ & $525 \pm 18$ \\
$\begin{array}{l}\text { Forskolin } 30 \mu \mathrm{M}+ \\
\text { NaF } 10 \mathrm{mM}\end{array}$ & $(7)$ & $478 \pm 16$ \\
\hline
\end{tabular}

Adenylate cyclase activity was expressed in pmol cyclic AMP produced. $\min ^{-1} \cdot \mathrm{mg}$ membrane protein ${ }^{-1}$ in the presence of $\mathrm{Gpp}(\mathrm{NH}) \mathrm{p}, \mathrm{NaF}$ and forskolin either alone or in combination with $\mathrm{Gpp}(\mathrm{NH}) \mathrm{p}$ or $\mathrm{NaF} ;(n)$ no. expt. The values were the mean \pm SEM. All stimulatory effects were significant but that observed when forskolin and $\mathrm{Gpp}(\mathrm{NH}) \mathrm{p}$ were added in combination was significantly lower than that observed with forskolin alone.

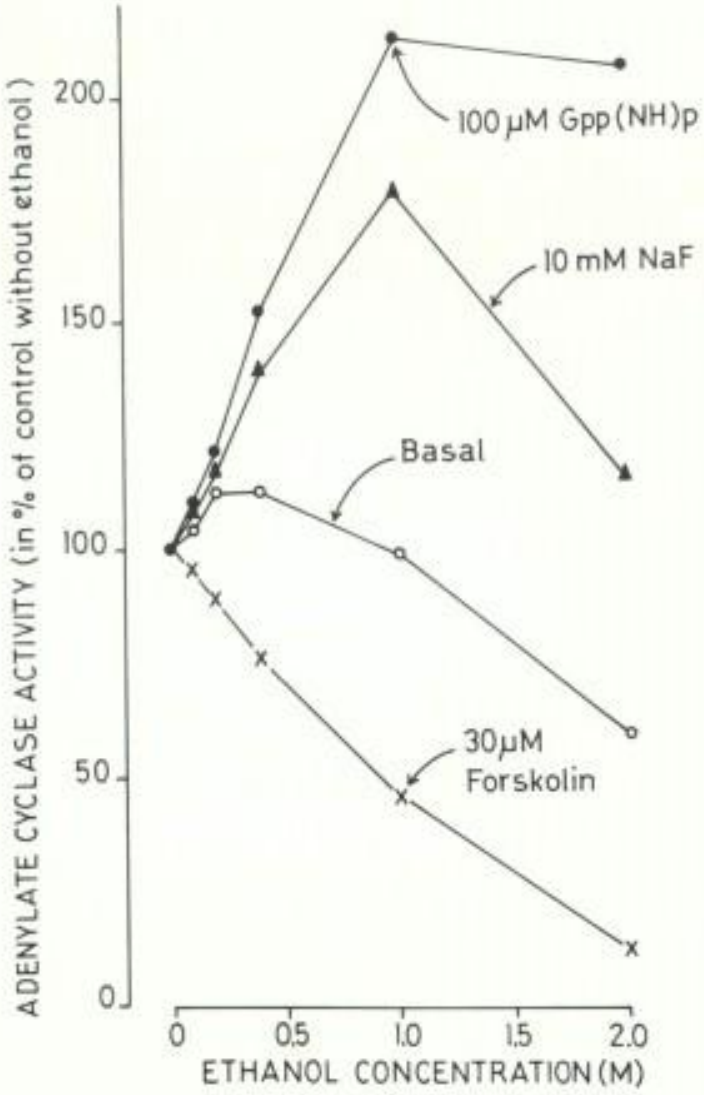

Fig.1. Effect of increasing concentrations of ethanol on basal $(0)$, and on $100 \mu \mathrm{M}$ Gpp(NH)p- $(\bullet), 10 \mathrm{mM} \mathrm{NaF}$ (A) and $30 \mu \mathrm{M}$ forskolin- (X) stimulated adenylate cyclase activity in rat heart membranes. The data are expressed as a percentage of the value observed for each stimulant in the absence of ethanol and are the means of at least 3 expt.

hibition of forskolin-stimulated adenylate cyclase activity was of a mixed type, involving a competitive and a non-competitive mechanism. The existence of a competitive factor is supported in fig. 3: the [ethanol] required for a $50 \%$ inhibition of forskolin-stimulated adenylate cyclase was significantly higher in the presence of $30 \mu \mathrm{M}$ forskolin than in the presence of $1 \mu \mathrm{M}$ forskolin.

The linear short-chain alcohols methanol, propanol and butanol were also able to inhibit forskolin stimulation (fig.4), their efficacy being directly related to the chain length. It was also observed that each alcohol concentration producing a $50 \%$ inhibition of forskolin-stimulated adenylate cyclase activity was able to potentiate the 


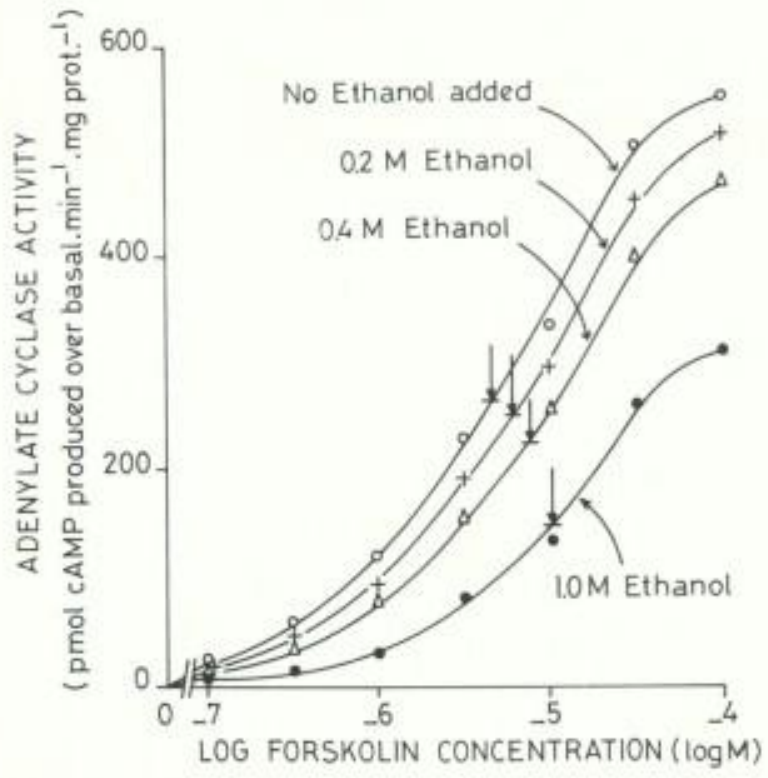

Fig.2. Dose-effect curves of stimulation of rat heart adenylate cyclase by forskolin in the absence $(0)$ or presence of $0.2 \mathrm{M}(+), 0.4 \mathrm{M}(\Delta)$ and $1.0 \mathrm{M}(\bullet)$ ethanol. The results, expressed in cyclic AMP produced. $\mathrm{min}^{-1} \cdot \mathrm{mg}$ membrane protein ${ }^{-1}$ (after subtraction of the basal value) were the means of 3 expt. ( $)$ [forskolin] required for half-maximal stimulation.

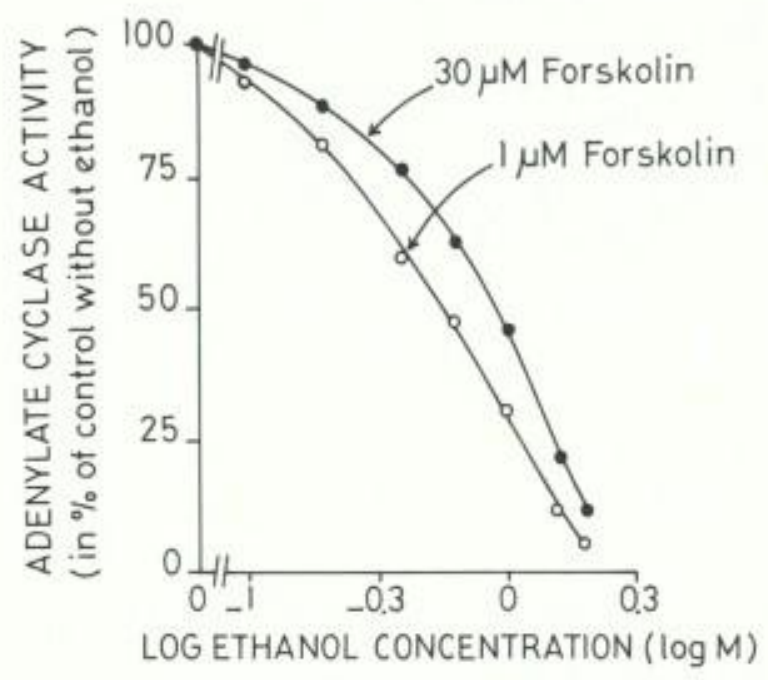

Fig.3. Inhibitory effects of increasing [ethanol] on rat heart adenylate cyclase activity stimulated by $1 \mu \mathrm{M}(0)$ and $30 \mu \mathrm{M}(\bullet)$ forskolin. The data are expressed as a $\%$ of the value observed in the absence of ethanol and are the means of 3 expt.

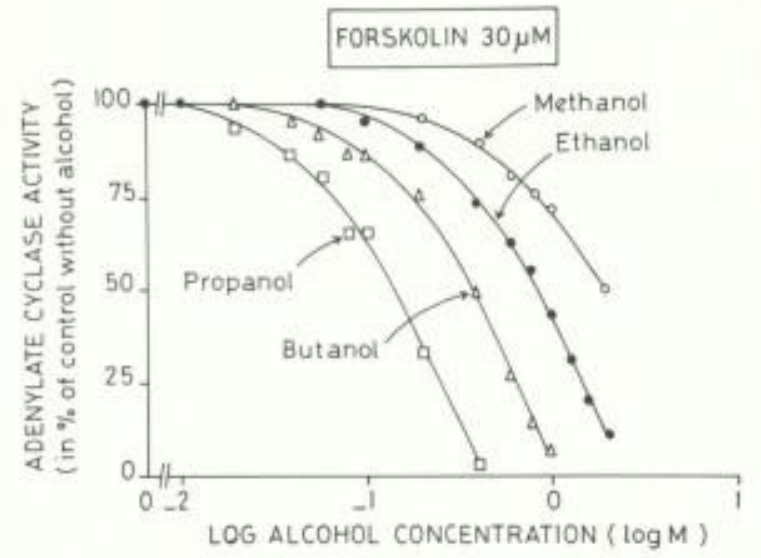

Fig.4. Inhibitory effects of increasing concentrations of methanol $(0)$, ethanol $(\bullet)$, propanol $(\Delta)$ and butanol (ㅁ) on rat heart adenylate cyclase activity stimulated by $30 \mu \mathrm{M}$ forskolin. The data are expressed as a $\%$ of the value observed in the absence of alcohol and are the means of 2 expt.

stimulatory effect of $\mathrm{Gpp}(\mathrm{NH}) \mathrm{p}$ and $\mathrm{NaF}$ on adenylate cyclase (not shown).

\section{DISCUSSION}

Alcohols cause biological and artificial membranes to expand and become more fluid [14]. This effect possibly mediates adenylate cyclase activation $[15,16]$ and inactivation $[8,9]$, depending on the alcohol concentration and the coupling state of adenylate cyclase components. Although their ultimate effects are on proteins, part of the mode of action of alcohols is thought to be mediated by their interactions with lipids [17].

These results show that 4 short-chain linear alcohols inhibited forskolin-stimulated adenylate cyclase at concentrations potentiating stimulatory effects of $\mathrm{NaF}$ and $\mathrm{Gpp}(\mathrm{NH}) \mathrm{p}$. The efficacy of the alcohols tested for inhibiting forskolin-stimulated adenylate cyclase activity was related to their chain length (i.e., to their partition coefficient) suggesting that the inhibition was related to their interaction with hydrophobic sites and possibly through a general perturbation in membrane dynamics.

Forskolin is, like alcohol, an amphiphilic hydrophobic compound and could conceivably act on the lipid matrix of cell membranes. Recent data comparing the efficacy of forskolin analogs as in- 
hibitors of human platelet aggregation [18] argue, however, against this interpretation. As forskolin activity is highly dependent on the presence of hydroxyl groups in a proper position, it is tempting to hypothesize that the diterpene is incorporated into the membrane bilayer at the interphase between adenylate cyclase components and lipids, so that active hydroxyl groups are in a critical configuration. Alcohols might then inhibit this positioning of forskolin as suggested by the mixed-type inhibition documented here.

Whatever the precise site of action of forskolin and alcohols, our data are of great practical interest. Forskolin is usually dissolved in ethanol and the diterpene effects are tested in the presence of ethanol concentrations that interfered significantly with drug activity in our system (dose-effect curves of forskolin were for instance obtained in the presence of $4 \%-0.8 \mathrm{M}$ ethanol in [19]). Thus, the values of $K_{\text {act }}$ and maximal efficacy of forskolin reported in the literature must be critically controlled.

\section{ACKNOWLEDGEMENTS}

This work was supported by grant 3.4504 .81 from the Fonds de la Recherche Scientifique Médicale (Belgium), and a grant from the Ministère de la Politique Scientifique (Belgium).

\section{REFERENCES}

[1] Seamon, K.B. and Daly, J.W. (1981) J. Cyclic Nucl. Res. 7, 201-224.

[2] Seamon, K.B., Padgett, W. and Daly, J.W. (1981) Proc. Natl. Acad. Sci. USA 78, 3363-3367.
[3] Seamon, K.B. and Daly, J.W. (1981) J. Biol. Chem. 256, 9799-9801.

[4] Insel, P.A., Stengel, D., Ferry, N. and Hanoune, J. (1982) J. Biol. Chem. 257, 7485-7490,

[5] Seamon, K.B. and Daly, J.W. (1982) J. Biol. Chem. 257, 11591-11596.

[6] Darfler, F.J., Mahan, L.C., Koachman, A.M. and Insel, P.A. (1982) J. Biol. Chem. 257, 11901-11907.

[7] Stock, K. and Schmidt, M. (1978) NaunynSchmiedberg's Arch. Pharmacol. 302, 37-43.

[8] Uhlemann, E.R., Robberecht, P. and Gardner, J.D. (1979) Gastroenterology 76, 917-925.

[9] Salesse, R., Garnier, J. and Daveloose, D. (1982) Biochemistry 21, 1587-1590.

[10] Grynne, B.H. and Toft, I.L. (1982) Acta Pharmacol. Toxicol. 50, 283-293.

[11] Fradkin, J.E., Cook, G.H., Kilhoffer, M.-C. and Wolff, J. (1982) Endocrinology 111, 849-856.

[12] Chatelain, P., Robberecht, P., De Neef, P., Camus, J.C., Heuse, D. and Christophe, J. (1980) Pflügers Arch. 389, 29-35.

[13] Salomon, Y., Londos, C. and Rodbell, M. (1974) Anal. Biochem. 58, 541-548.

[14] Chin, J.H. and Goldstein, D.B. (1977) Science 196, 684-685.

[15] Hanski, E., Rimon, G. and Levitzki, A. (1979) Biochemistry 18, 846-853.

[16] Houslay, M.D., Dipple, I., Rawal, S., Sauerheber, R.D., Esgate, J.A. and Gordon, L.M. (1980) Biochem. J. 190, 131-137.

[17] Franks, N.P. and Lieb, W.R. (1982) Nature 300, 487-493.

[18] Adnot, S., Desmier, M., Ferry, N. and Hanoune, J. (1982) Biochem. Pharmacol. 31, 4071-4074.

[19] Clark, R.B., Goka, T.J., Green, D.A., Barber, R. and Butcher, R.W. (1982) Mol. Pharmacol. 22, 609-613. 